\title{
RF Magnetron Sputtering Aluminum Oxide Film for Surface Passivation on Crystalline Silicon Wafers
}

\author{
Siming Chen, Luping Tao, Libin Zeng, and Ruijiang Hong \\ Institute for Solar Energy Systems, School of Engineering, Sun Yat-sen University, \\ Guangzhou Higher Education Mega Center, Guangzhou 510006, China \\ Correspondence should be addressed to Ruijiang Hong; hongruij@mail.sysu.edu.cn
}

Received 30 October 2012; Revised 18 December 2012; Accepted 26 December 2012

Academic Editor: Ho Chang

Copyright (c) 2013 Siming Chen et al. This is an open access article distributed under the Creative Commons Attribution License, which permits unrestricted use, distribution, and reproduction in any medium, provided the original work is properly cited.

Aluminum oxide films were deposited on crystalline silicon substrates by reactive RF magnetron sputtering. The influences of the deposition parameters on the surface passivation, surface damage, optical properties, and composition of the films have been investigated. It is found that proper sputtering power and uniform magnetic field reduced the surface damage from the high-energy ion bombardment to the silicon wafers during the process and consequently decreased the interface trap density, resulting in the good surface passivation; relatively high refractive index of aluminum oxide film is benefic to improve the surface passivation. The negative-charged aluminum oxide film was then successfully prepared. The surface passivation performance was further improved after postannealing by formation of an $\mathrm{SiO}_{x}$ interfacial layer. It is demonstrated that the reactive sputtering is an effective technique of fabricating aluminum oxide surface passivation film for low-cost high-efficiency crystalline silicon solar cells.

\section{Introduction}

Surface passivation is still one of the most important techniques to improve the performance of low-cost highefficiency industrial solar cells. There are two different strategies to achieve surface passivation, which are (i) reducing the interface trap density by passivating dangling bonds with, for example, $\mathrm{H}$ atomic or a thin dielectric film like $\mathrm{SiO}_{x}$, which is commonly referred to as chemical passivation, and (ii) socalled field-effect passivation that a reduction of minority carrier concentration is obtained by means of a built-in electric field [1].

Recently, aluminum oxide film has demonstrated the capability of providing excellent surface passivation on both p-type and low-resistivity $n$-type surfaces of silicon wafers and solar cells [2-10] by its high density of fixed negative charge, which is one of the special characteristics of the aluminum oxide film. To activate the surface passivation of aluminum oxide film, a postannealing has to be accomplished subsequently to deposition processes regardless of the deposition techniques. A very thin layer of $\mathrm{SiO}_{x}$ is proved to exist at silicon interface [5]. This $\mathrm{SiO}_{x}$ interfacial layer is crucial to form the fixed negative charge, as well as to diminish the density of interface traps, which are the two approaches to realize excellent passivation.

Among the multifarious techniques adopted to fabricate aluminum oxide film, atomic layer deposition (ALD) has turned out to be a technique providing outstanding surface passivation to laboratory high-efficiency solar cells $[4,11]$. However, the low deposition rate and high cost facilities of ALD technique limit its application in large-scale production $[1,4]$. We thus proposed a novel method using RF magnetron sputtering coater which is assured to overcome both shortcomings of ALD technique. As the surface passivation of reactive sputtered aluminum oxide film is mainly limited by high interface traps density while fixed negative charge of sputtered films is similar to that deposited by $\operatorname{ALD}[7,9,10]$, proper sputtering parameters, proper sputtering power, for instance, can reduce the surface damage caused by highenergy ions bombardment during the process and result in the reduction of interface trap density.

In the present study, we varied the RF sputtering power during the sputtering of aluminum oxide films. The minority carrier lifetime was measured to investigate the surface passivation performance. Besides, photoluminescence (PL), 
TABLE 1: The deposition rate of different sputtering powers measured by n\&k Analyzer 1200 .

\begin{tabular}{lc}
\hline Power $(\mathrm{W})$ & Deposition rate $(\mathrm{nm} / \mathrm{min})$ \\
\hline 600 & 4.862 \\
800 & 6.893 \\
1000 & 8.997 \\
1200 & 11.256 \\
1400 & 12.678 \\
1600 & 14.288 \\
\hline
\end{tabular}

refractive index, and XPS were also implemented to characterize the properties of the aluminum oxide films.

\section{Experimental Details}

A batch of $125 \times 125 \mathrm{~mm}^{2}$ (100) Czochralski p-type silicon wafers with resistivity of $1-3 \Omega \mathrm{cm}$ was prepared. The wafers underwent a 5 min saw-damage etching, HF dip, and deionized water rinse prior to the RF deposition. The aluminum oxide films were deposited in an RF magnetron sputtering coater equipped with an OMAT cathode and HUETTINGER electronic PFG 5000 RF power supplies. The cathode is configured with a planar annular permanent magnetic source. A $99.99 \%$ aluminum target, which is $100 \mathrm{~mm}$ in radius and $5 \mathrm{~mm}$ in thickness, was reactively sputtered with $1 \mathrm{sccm}$ of $\mathrm{O}_{2}$ and $10 \mathrm{sccm}$ of $\mathrm{Ar}$ at a pressure of $0.6 \mathrm{~Pa}$. The RF power varied from 600 to $1600 \mathrm{~W}$, with DC self-bias voltages around $170-220 \mathrm{~V}$. The deposition rate at different sputtering powers is tabulated as Table 1. All of the samples were deposited about $50 \mathrm{~nm}$ of aluminum oxide films on both sides of the wafers at room temperature, to create a symmetrical lifetime structure for minority carrier lifetime testing. And a postannealing was performed in a quartz tube furnace at $500^{\circ} \mathrm{C}$ in a $\mathrm{N}_{2}$ ambient for $30 \mathrm{~min}$.

Minority carrier lifetime of the samples was measured by means of microwave photoconductivity decay ( $\mu$-PCD) using a Semilab WT2000 to obtain the mappings of minority carrier lifetime. The PL images were taken to analyze the surface damage to the wafers sputtered at different sputtering powers by using a $3 \mathrm{i}$ systems corporation FL-B01 EL\&PL allin-one tester. To characterize the aluminum oxide thin films, the refractive indices of the films were measured with an n\&k Technology n\&k Analyzer 1200. ESCALAB 250 X-ray photoelectron spectroscopy (XPS) system was performed to analyze the element composition and the atom ratio in the thin films.

\section{Results and Discussion}

3.1. Effect of Surface Damage on Surface Passivation. Minority carrier lifetime mappings are shown in Figure 1 and reveal that the minority carrier lifetime distributions of these passivated $\mathrm{CZ}$ wafers are nonuniform. For the planar annular permanent magnetic source, it is observed that, as the power increased, the higher minority carrier lifetime areas spread along the cyclic annular region where the density of magnetic line of force is higher and distribution is much more uniform, thus the sputtering processes the most frequently and regularly. Comparing the minority carrier lifetime mappings with their corresponding PL images in Figure 1, it is found that the higher minority carrier lifetime regions are much brighter in all the samples, which shows that these regions get less surface damage from high-energy ions during sputtering.

Figure 2 shows the varying sputtering power during the deposition process in order to achieve the corresponding minority carrier lifetime averaging over the wafer area according to Figure 1, as well as the relationship between the power and the maximum values of the minority carrier lifetime measured with WT2000 for all the samples. It is indicated that the sample deposited by RF magnetron sputtered aluminum oxide at $1000 \mathrm{~W}$ has the highest average lifetime $29.443 \mu \mathrm{s}$, and the maximum lifetime reaches up to $134.59 \mu \mathrm{s}$, while the other average lifetime is just around or below $10 \mu \mathrm{s}$, and the maximum lifetime is less than $50 \mu \mathrm{s}$. As shown in the PL image in Figure 1(c), the brightest region in all the samples spreads in the annular region where the highest minority carrier lifetime locates.

Thus, the proper sputtering power and uniform magnetic field reduce the surface damage from high-energy ion during sputtering, consequently reduce the interface trap density, and result in better passivation quality.

3.2. Effect of Optical Properties on Surface Passivation. The refractive index of the film, to a certain extent, indicates the thin film quality. So establishing the relationship between the refractive index of aluminum oxide film to the minority carrier lifetime is useful to figure out how the thin film quality influences the surface passivation. As shown in Figure 3, it is illustrated that the trend of refractive index is approximately consistent with the minority carrier lifetime. The largest refractive index is 1.584 at the sputtering power of $1000 \mathrm{~W}$, where the highest minority carrier lifetime is achieved. But it is lower than 1.65 , which is commonly referred to as the refractive index of amorphous $\mathrm{Al}_{2} \mathrm{O}_{3}$ [9].

Figure 4 reveals the minority carrier lifetime and the refractive index as a function of the radius of the wafer passivated by RF sputtering aluminum oxide at $1000 \mathrm{~W}$ and after a $30 \mathrm{~min}$ postannealing at $500^{\circ} \mathrm{C}$ in $\mathrm{N}_{2}$ ambient. The green curve is the line scan of minority carrier lifetime mapping along the dashed line as shown in Figure 1(c). It is obtained that the highest minority carrier lifetime locating in the radius of around $50 \mathrm{~mm}$ is nearly $75 \mu \mathrm{s}$. The refractive indices which were measured along the dashed line in Figure 1(c) at the radius of $0,25 \mathrm{~mm}, 50 \mathrm{~mm}, 65 \mathrm{~mm}$, $75 \mathrm{~mm}$ and plotted in Figure 4 demonstrate that the refractive indices of the film are also approximately consistent with the minority carrier lifetime, the same as the situation discussed previously. We obtained the largest refractive index 1.584 at the radius of $50 \mathrm{~mm}$ where the best result of minority carrier lifetime is achieved.

With respect to the previous discussion, it is likely to indicate the larger refractive index of the aluminum oxide film conducting much compacter structure and better quality of the film that is considerably more helpful to form fixed 


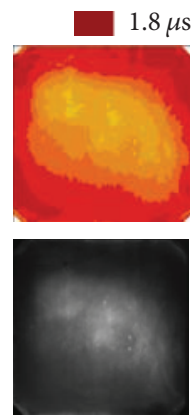

(a) $600 \mathrm{~W}$
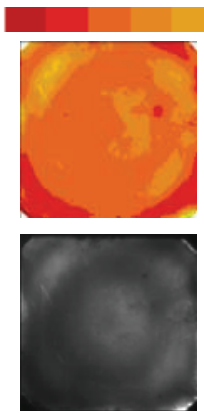

(b) $800 \mathrm{~W}$

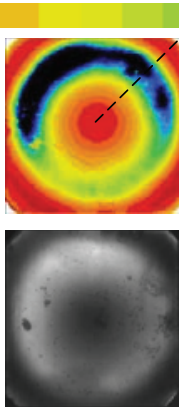

(c) $1000 \mathrm{~W}$

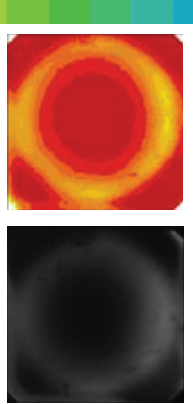

(d) $1200 \mathrm{~W}$

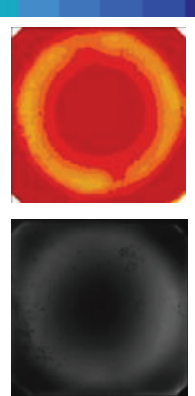

(e) $1400 \mathrm{~W}$
$67 \mu \mathrm{s}$

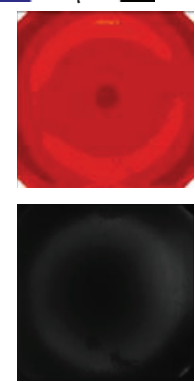

(f) $1600 \mathrm{~W}$

FIGURE 1: Minority carrier lifetime mappings and PL images of $125 \times 125 \mathrm{~mm}^{2} \mathrm{CZ}$ wafers passivated by RF magnetron sputtered aluminum oxide at different sputtering powers and after a 30 min postannealing at $500^{\circ} \mathrm{C}$ in $\mathrm{N}_{2}$ ambient. Upper row: minority carrier lifetime mappings. Lower row: PL images.

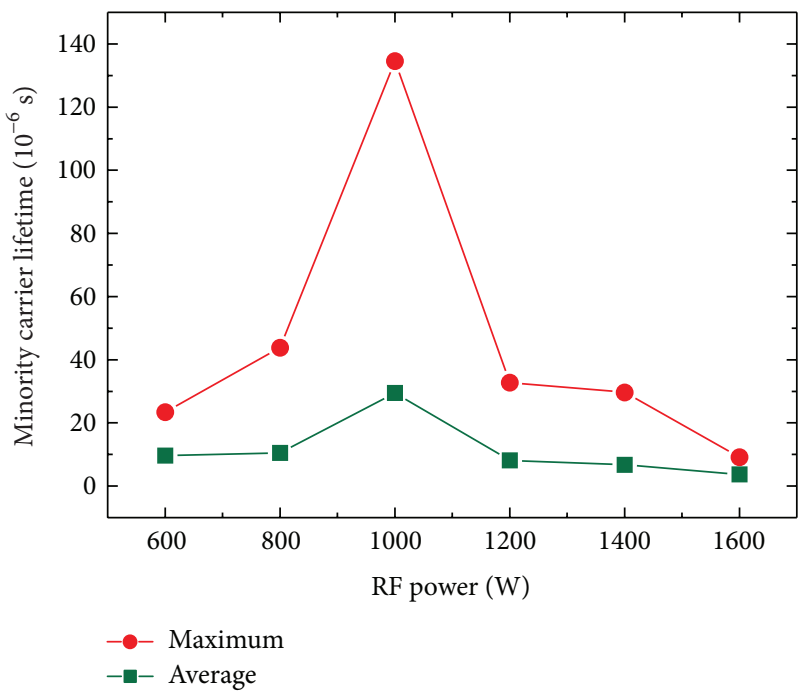

FIGURE 2: The average and maximum minority carrier lifetime of the wafers areas as related to the sputtering powers according to Figure 1.

negative charge and reduce interface trap density as well. And the high minority carrier lifetime is obtained as a result.

\subsection{Effect of Composition on the Film Structure. An XPS} depth profile measurement of the aluminum oxide film deposited at $1000 \mathrm{~W}$ RF power and after annealing at $500^{\circ} \mathrm{C}$ for $30 \mathrm{~min}$ in $\mathrm{N}_{2}$ ambient was made in order to determine the chemical composition distribution across the film thickness and to analyze the interface between the film and Si substrate according to the etch time. The $\mathrm{O} / \mathrm{Al}$ ratio of the deposited film shown in Figure 5 is around 2.0, larger than the $\mathrm{Al}_{2} \mathrm{O}_{3}$ stoichiometry that is 1.5 , which probably results in the lower refractive index 1.584 than that of amorphous $\mathrm{Al}_{2} \mathrm{O}_{3} 1.65$.

Figure 6(a) shows the change in the Si $2 p$ XPS spectra of the aluminum oxide film sputtered by $1000 \mathrm{~W}$ RF power as deposited and after $30 \mathrm{~min}$ of annealing at $500^{\circ} \mathrm{C}$ in $\mathrm{N}_{2}$ ambient which were detected at the etch time of $780 \mathrm{~s}$. The

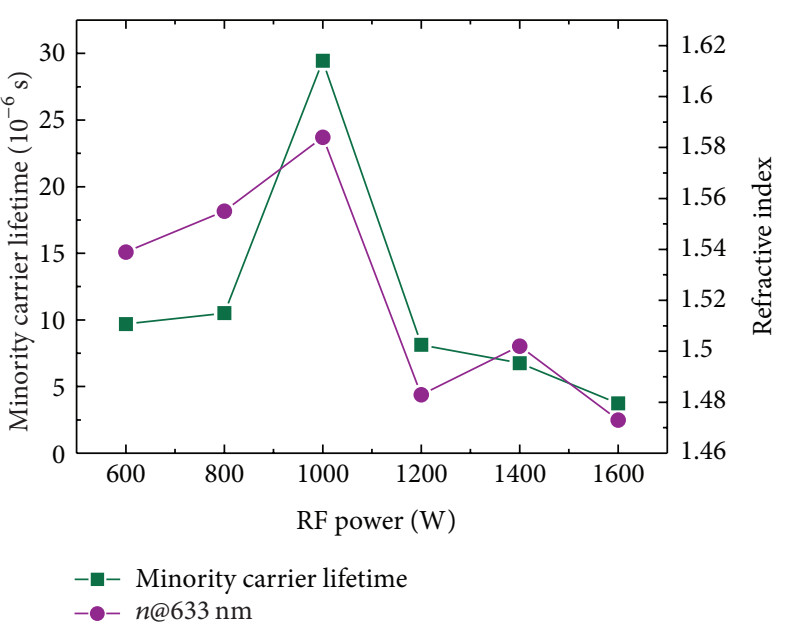

FIGURE 3: The relationship between the minority carrier lifetime and the sputtering power to the refractive index of the aluminum oxide films.

$\mathrm{Si}^{0}$ peaks attributable to the $\mathrm{p}$-type $\mathrm{Si}$ substrate are observed at 99 and $99.5 \mathrm{eV}$ for both spectra; broad peaks appearing in the range from 101.5 to $105 \mathrm{eV}$ are related to various Si compound fitted by synthetic peak model illustrated in Figure 6(b) and are characteristic of $\mathrm{SiO}_{x}$ formation for the core-level energy $103.3 \mathrm{eV}$ of $\mathrm{Si}^{4+}$ component corresponding to $\mathrm{SiO}_{2}$. For the annealed aluminum oxide film, the counts of the broad peak representing the $\mathrm{SiO}_{x}$ formation from 101.5 to $105 \mathrm{eV}$ increase, indicating that more $\mathrm{SiO}_{x}$ formed at the interfacial layer and improved the level of surface passivation after postannealing.

As it has been reported in the literatures [2-10], the $\mathrm{SiO}_{x}$ interfacial layer is crucial to form fixed negative charge and reduce interface trap density. For the good surface passivation performance obtained by sputtering aluminum oxide film at $1000 \mathrm{~W}$ after postannealing, it proposes the evidence that the $\mathrm{SiO}_{x}$ exists in the interfacial layer between aluminum oxide and $\mathrm{Si}$ substrate, which ultimately leads to the high level of surface passivation. The vertical dashed lines 


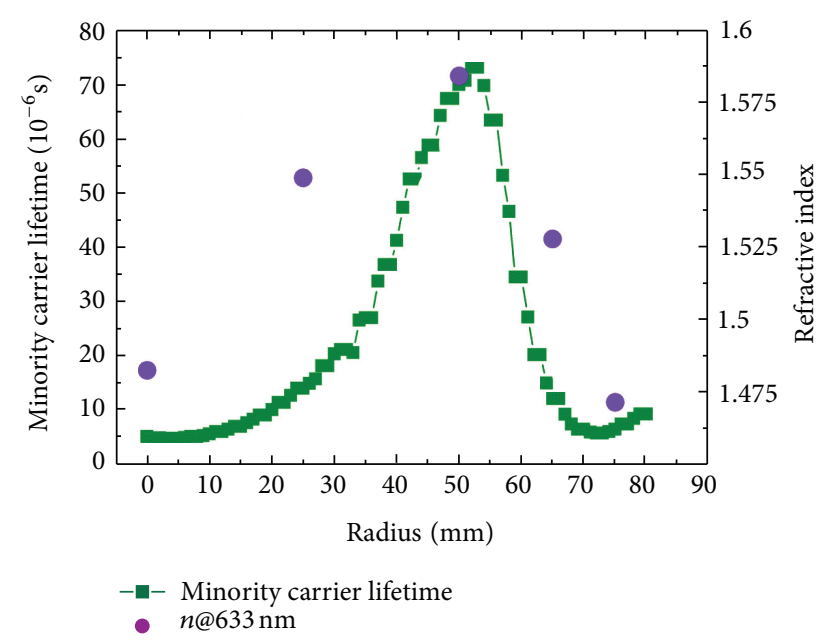

Figure 4: The minority carrier lifetime and the refractive index as related to the radius of the wafer passivated by RF sputtering aluminum oxide at $1000 \mathrm{~W}$ and after a $30 \mathrm{~min}$ postannealing at $500^{\circ} \mathrm{C}$ in $\mathrm{N}_{2}$ ambient.

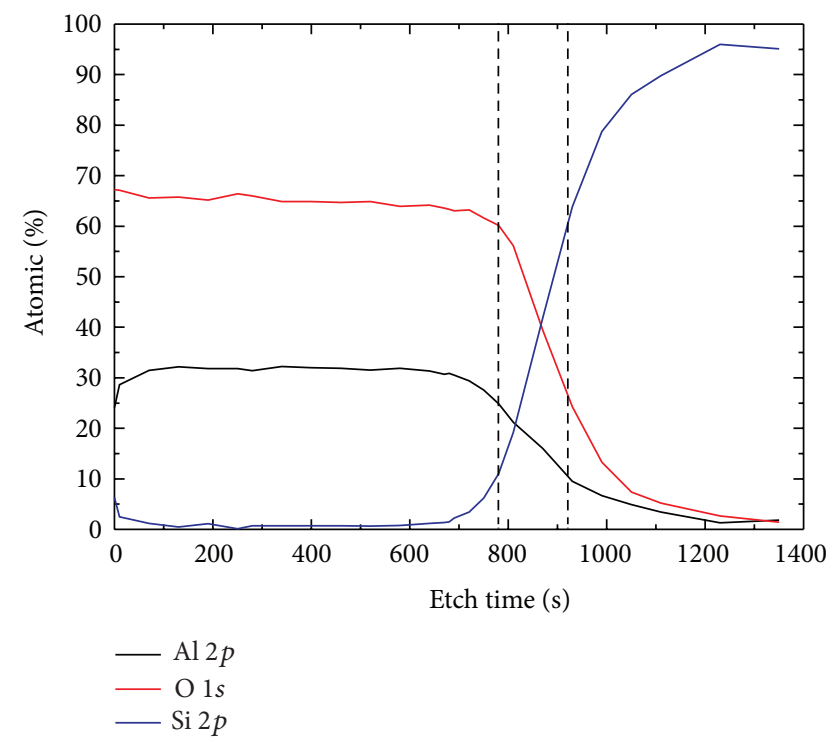

FIGURE 5: The XPS element composition depth profile of a sputtered aluminum oxide film at the power of $1000 \mathrm{~W}$ and after postannealing at $500^{\circ} \mathrm{C}$ in $\mathrm{N}_{2}$ ambient for $30 \mathrm{~min}$ as related to the etch time. The vertical dashed lines mark the approximate location of the interfacial layer between the aluminum oxide film and Si substrate.

as shown in Figure 5 mark the approximate location of the $\mathrm{SiO}_{x}$ interfacial layer between the aluminum oxide film and the Si substrate.

It is known that ALD techniques including thermal ALD and plasma-assisted ALD provide the best surface passivation by depositing aluminum oxide, but ALD techniques are not the best methods for the industrial solar cells production, because the deposition rate of ALD is limited below $2 \mathrm{~nm} / \mathrm{min}$ [12]. Recently, it is proposed a spatial ALD concept

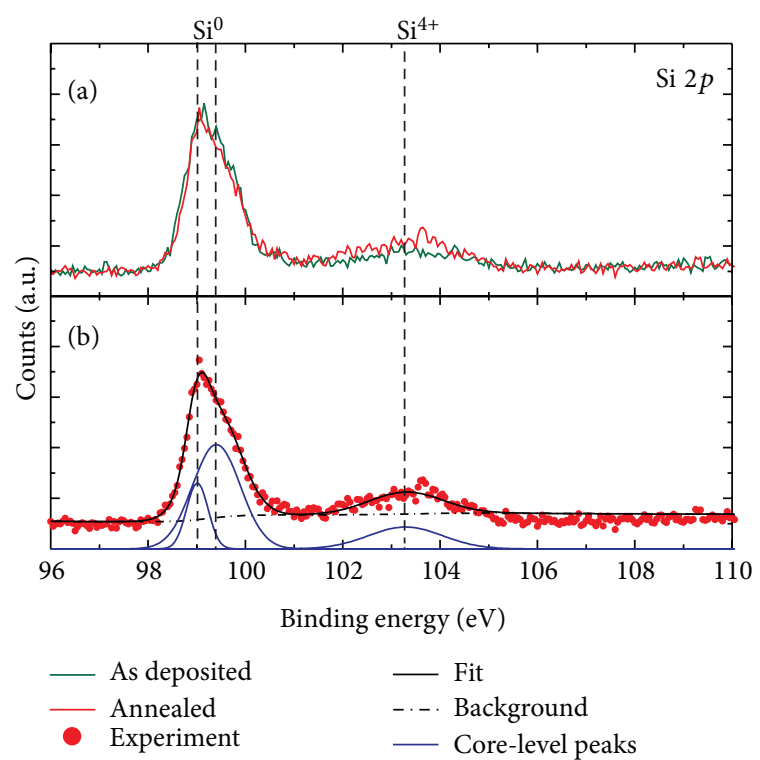

FIgUre 6: (a) The Si $2 p$ XPS spectra of the aluminum oxide film sputtered at $1000 \mathrm{~W}$ RF power as-deposited and after $30 \mathrm{~min}$ of annealing at $500^{\circ} \mathrm{C}$ in $\mathrm{N}_{2}$ ambient which were detected at the etch time of $780 \mathrm{~s}$. (b) Si $2 p$ core-level spectrum fitted by using a synthetic peak model for the aluminum oxide film sputtered at $1000 \mathrm{~W}$ and after postannealing.

with deposition rate of up to $70 \mathrm{~nm} / \mathrm{min}$ [13] carried out in the spatial domain, while the conventional ALD cycles are carried out in the time domain. But the extremely expensive facilities are still the restriction of spatial ALD application in industrial solar cells production.

On the contrary, the RF magnetron sputtering of $50 \mathrm{~nm}$ of aluminum oxide thin film requires less than six minutes by the laboratory system in this study (see Table 1; the deposition rate of $1000 \mathrm{~W}$ sputtering power is $8.997 \mathrm{~nm} / \mathrm{min}$ ). As it is reported that the thickness of aluminum oxide film can be less than $30 \mathrm{~nm}[2,4]$, the deposition of aluminum oxide thin film can be faster, more uniform, and over larger areas in industrial setup, for example, magnetron sputtering array system. The low cost of the sputtering equipments and the outstanding surface passivation performance indicate that the reactive RF sputtering has an enormous potential for a transfer of aluminum oxide passivation technique into lowcost high-efficiency solar cells production, which is the most important approach for industry to get through the present crisis of heavy overcapacity and demand compression. We have analyzed the influence of sputtering power on the surface passivation of reactive RF sputtered aluminum oxide. Other sputtering parameters will continue to be investigated with further research; it is necessary for introducing the technique to the industrial solar cell manufacturing.

\section{Conclusions}

As we revealed in this paper, proper sputtering power and uniform magnetic field produce less surface damage to wafers that is helpful to reduce the interface trap density; relatively 
high refractive index aluminum oxide film is much more conducive to improve the surface passivation performance; the formation of the $\mathrm{SiO}_{x}$ is detected at the interfacial layer after postannealing that is vital to achieve good surface passivation by RF magnetron sputtered aluminum oxide film. We summarized that the proper sputtering parameters and formation of the $\mathrm{SiO}_{x}$ interfacial layer are crucial to determine the surface passivation performance provided by reactive RF magnetron sputtered aluminum oxide film, including the sputtering power, working pressure, and postannealing technique. Furthermore, as RF magnetron sputtering meets both requirements of low cost of facilities and high rate of deposition, it is an effective method of surface passivation and quite suitable for low-cost high-efficiency solar cells manufacturing.

\section{References}

[1] L. T. Liang, "Technology of Semiconductor Device Surface Passivation," 1979.

[2] G. Agostinelli, A. Delabie, P. Vitanov et al., "Very low surface recombination velocities on p-type silicon wafers passivated with a dielectric with fixed negative charge," Solar Energy Materials and Solar Cells, vol. 90, no. 18-19, pp. 3438-3443, 2006.

[3] B. Hoex, J. J. H. Gielis, M. C. M. van de Sanden, and W. M. M. Kessels, "On the c-Si surface passivation mechanism by the negative-charge-dielectric $\mathrm{Al}_{2} \mathrm{O}_{3}$," Journal of Applied Physics, vol. 104, Article ID 113703, 7 pages, 2008.

[4] J. Schmidt, A. Merkle, R. Brendel, B. Hoex, M. C. M. van de Sanden, and W. M. M. Kessels, "Surface passivation of highefficiency silicon solar cells by atomic-layer-deposited $\mathrm{Al}_{2} \mathrm{O}_{3}$," Progress in Photovoltaics: Research and Applications, vol. 16, no. 6, pp. 461-466, 2008.

[5] G. Dingemans, N. M. Terlinden, M. A. Verheijen, M. C. M. van de Sanden, and W. M. M. Kessels, "Controlling the fixed charge and passivation properties of $\mathrm{Si}(100) / \mathrm{Al}_{2} \mathrm{O}_{3}$ interfaces using ultrathin $\mathrm{SiO}_{2}$ interlayers synthesized by atomic layer deposition," Journal of Applied Physics, vol. 110, Article ID 093715, 6 pages, 2011.

[6] S. Miyajima, J. Irikawa, A. Yamada, and M. Konagai, "Hydrogenated aluminium oxide films deposited by plasma enhanced chemical vapor deposition for passivation of p-type crystalline silicon," in Proceedings of the 23rd European Photovoltaic Solar Energy Conference, pp. 1029-1032, Valencia, Spain, September 2008.

[7] T. T. Li and A. Cuevas, "Effective surface passivation of crystalline silicon by rf sputtered aluminum oxide," Physica Status Solidi RRL, vol. 3, p. 16, 2009.

[8] G. Dingemans and W. M. M. Kessels, "Recent progress in the development and understanding of silicon surface passivation by aluminum oxide for photovoltaics," in Proceedings of the 25th European Photovoltaic Solar Energy Conference, pp. 1083-1090, Valencia, Spain, September 2010.

[9] T. T. Li, S. Ruffell, M. Tucci et al., "Influence of oxygen on the sputtering of aluminum oxide for the surface passivation of crystalline silicon," Solar Energy Materials \& Solar Cells, vol. 95, no. 1, pp. 69-72, 2011.

[10] T. T. Li and A. Cuevas, "Role of hydrogen in the surface passivation of crystalline silicon by sputtered aluminum oxide,"
Progress in Photovoltaics: Research and Applications, vol. 19, pp. 320-325, 2011.

[11] J. Benick, B. Hoex, M. C. M. van de Sanden, W. M. M. Kessels, O. Schultz, and S. W. Glunz, "High efficiency $n$-type Si solar cells on $\mathrm{Al}_{2} \mathrm{O}_{3}$-passivated boron emitters," Applied Physics Letters, vol. 92, Article ID 253504, 3 pages, 2008.

[12] A. Cuevas, A. Li, F. Roozeboom et al. Photovoltaics International, 10th edition, 2010.

[13] F. Werner, W. Stals, R. Görtzen, B. Veith, R. Brendel, and J. Schmidt, "High-rate atomic layer deposition of $\mathrm{Al}_{2} \mathrm{O}_{3}$ for the surface passivation of Si solar cells," Energy Procedia, vol. 8, pp. 301-306, 2010. 

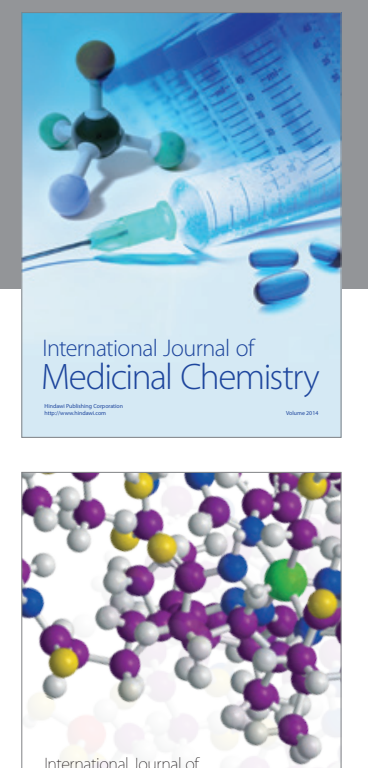

\section{Carbohydrate} Chemistry

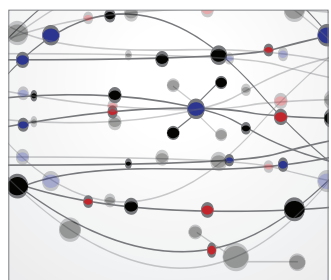

The Scientific World Journal
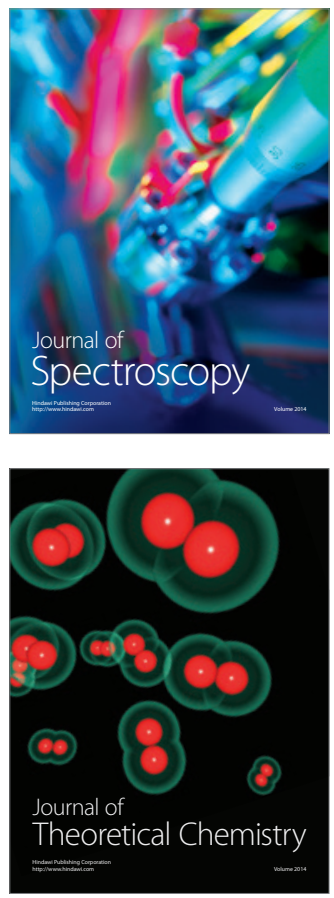
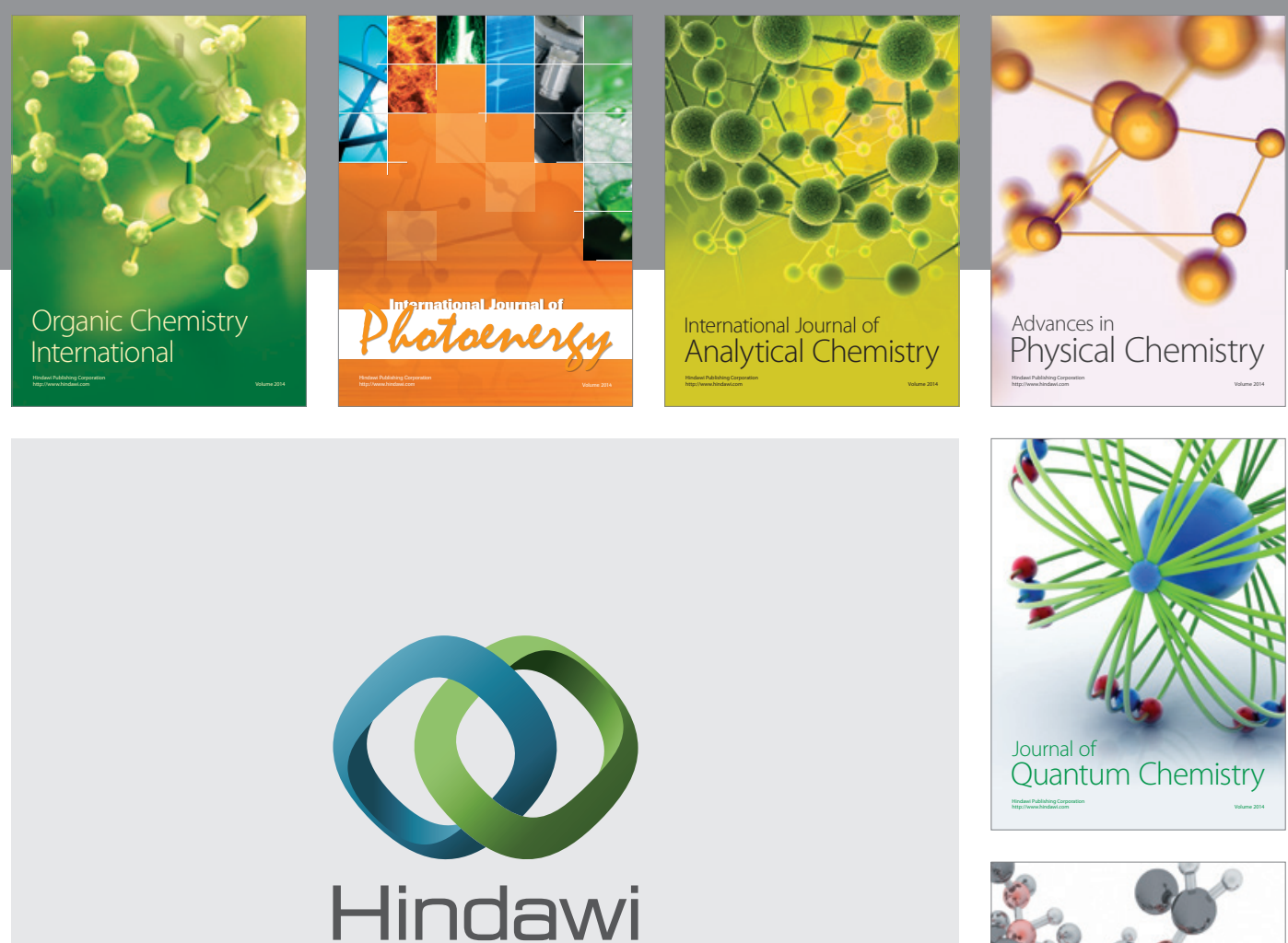

Submit your manuscripts at

http://www.hindawi.com

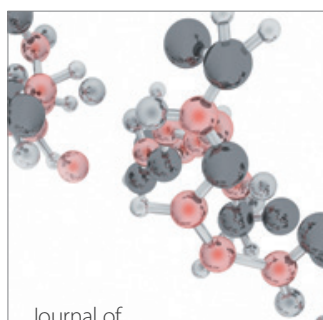

Analytical Methods

in Chemistry

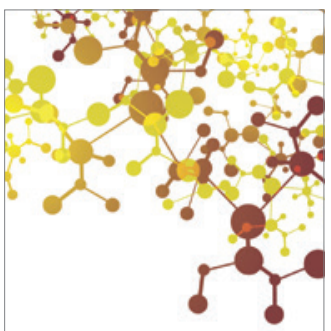

Journal of

Applied Chemistry

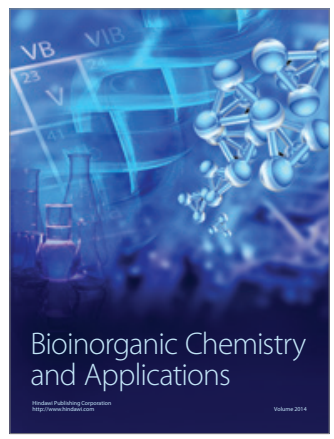

Inorganic Chemistry
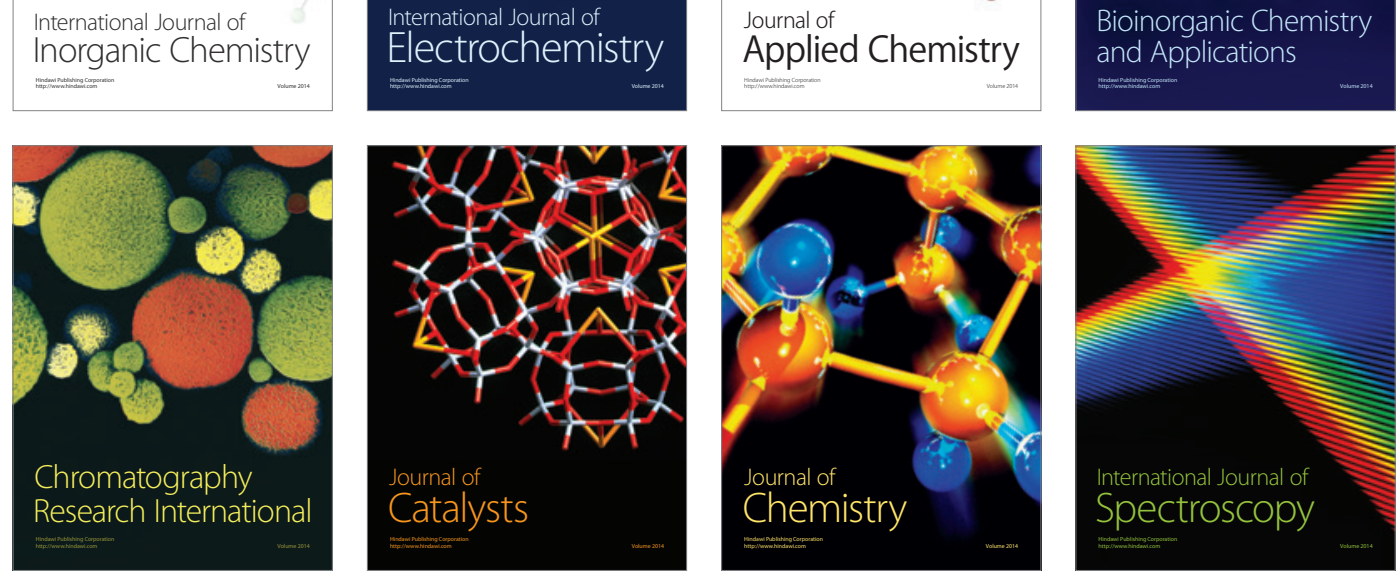